\title{
The Enlightenment of Folk Belief Activities in Drought and Epidemic Crisis on Education
}

\author{
Yang Xiulan \\ Xi'an University, Shaanxi, China, 710065
}

Keywords: Moment of Crisis; Drought; Disease; Folk Believes; Enlightenment

Abstract: As a historical and cultural phenomenon, folk belief activities are permeated in many aspects of people's lives. Studying the folk belief activities during drought and epidemic crisis will help to understand the emergency measures and folk belief activities during historical crisis, so it has far-reaching significance for education. It not only enhances people's ability and psychological preparation for coping with the crisis, but also promotes to achieve a cooperative consensus in response to the crisis in education, which is very meaningful for stabilizing society. This paper deals with two major disasters: starting from drought, it firstly states the historical records, causes and hazards of drought, and elaborates on the origin and progress of the folk belief activities in the crisis of "rain praying". Secondly, when clarifying the belief activities brought about by diseases and their hazards, this paper takes the examples in different cultures and different countries, which lead to the same result. In the face of a huge crisis, people hope to use the mysterious power of the outside work to seek security, which is regarded as the initial motive of the folk belief activities at critical moments. How to scientifically respond to the crisis and reduce damage and loss is an important inspiration for studying the education of folk beliefs during crises.

Folk beliefs and culture are closely related to the lives of the people. The critical moment here refers to the time when the society or the country is facing huge disasters or serious threats, which even causes a large number of populations to disappear, endangering the safety of the national body with the stagnation or even regression of social production and life, and it is hardly to survive. The folk activities that occur at this moment often have very clear motives and purposes, and the venues are relatively fixed. Studying the folk belief activities at critical moments can help to improve the measures to deal with social crisis, and it is also an important way to deeply understand the traditional folk culture phenomenon.

In ancient society, according to the History of Song Dynasty volume 431 The Confucian Biography: "the people are suffering from four disasters: plague, drought, flood, and animal diseases. All disasters are of the four categories of varying degrees of severity. And among the four disasters, drought is the most serious." It means that there were four types of serious disasters for people at that time: 1 . Plague - mainly refers to infectious diseases that occur in humans and cause a large number of deaths. It was almost an incurable infective disease at that time; 2 . Drought - a very frequent natural disaster with crop failure caused by lack of rain, and people were famine and suffering from displacement; 3. Flood - It often occurs during rainy seasons. 4.Animal diseases-- it 
refers to animal plague or a large number of deaths caused by natural disasters. For example, in the winter, frosted livestock are frozen to death in large quantities due to snowfall. This paper mainly discusses the enlightenment of folk belief activities to education when drought and plague disasters seriously endanger people's lives.

\section{Drought Hazards and Folk Belief Activities in History}

According to Pi Qingsheng's Study on the Faith of the People in the Song Dynasty, when people's meteorological knowledge of the nature is insufficient, it is believed that the human beings cannot expect the meteorological incidents and only the specialized talents can know one or two. Whenever in drought, praying for rain is very important event. "The rain praying activities in different forms and of different scales will be held in the disaster-stricken areas, and all groups of the society must participate, so praying for rain has become an occasion where various forces meet. With the praying rain as the entry point, you can understand the people's beliefs and customs at one time and one place, and you can also examine the relationship between various social forces involved in praying for rain." It is said that all walks of life have to participate in rain praying, so its extensiveness is self-evident. From the national ceremony to the local sacrifices, there is participation in the "rain praying" activity.

\subsection{Causes of Droughts}

The Yellow River Basin mainly belongs to the temperate monsoon climate with semi-arid and sub-humid areas. In spring and summer, most of the natural disasters in most parts of northern China and the middle and lower reaches of the Yellow River are droughts. In spring, the temperature rises rapidly and the transpiration is getting stronger. It is the time when the crops need to return to the green water. The rainfall is scarce and it is easy to cause spring drought due to lack of water. In the summer, it is hot and dry with insufficient water, so drought often occurs.

\subsection{Major Droughts in History and Their Hazards}

Several famous droughts in history:

The third year of Kangxi Emperor: It did not rain in summer with no harvest in autumn and no snow in winter, which led to great drought. Foot could not be harvested, so people suffered from famine. The eighth year of Qianlong Emperor: There was a great drought. Pedestrians were so hot to death, and no food was harvested. The first year of Guangxu Emperor: After three consecutive years of drought, the people were hungry and the roots of the bark were eaten. The tree was dead. The people were suffering.

\subsection{The Social Crisis Brought by the Drought and the Background of the Rain Praying}

The drought has occurred many times in the northern part of China, covering extensive area with high frequency and great hazards, and the people are deeply affected. The people panic and could do nothing. In the struggle between man and nature, human power is rather weak. Social production is almost stagnant, and it is difficult for the country or the locality to spend food and huge amounts of money. In the 275 years of the 16th year of Hongwu and Chongzhen in the Ming Dynasty, there were 114 droughts, and 4 droughts occurred in an average of 10 years. In the 267 years from the first year of Shunzhi to the third year of Xuantong in the Qing Dynasty, there were 119 droughts, with an average of 4.5 occurrences in 10 years. During the Republic of China, droughts occurred almost every year. When the drought began, the food was not harvested, the famine was everywhere, 
the sorrows were everywhere, the people had no food to eat and survived depending on the bark and grass, the hunger people were panicked, the rich were flustered, which seriously threatened the national security and social production. Therefore, the rulers of the past dynasties did not dare to neglect the drought. The measures taken generally included two aspects: one was to resist disasters through relief and fundraising; the other was to ease the drought by praying for rain to specific gods. From the perspective of folk beliefs, this paper mainly discusses the following second aspect.

\subsubsection{The object of rain praying}

The objects of praying for rain are the wind and thunder, the god of lightning, and the dragon king. This is influenced by Zhu Yuanzhang's "the temple is of great importance to the country" in the early years of the Ming Dynasty. The praying rain is mainly carried out in the Fengshen Thunderstorm Mountain, the Taishan Palace, the Dragon King Temple, etc. These gods are within the scope of the national sacrifices, and are also the places of worship in the provinces and counties of the provinces. According to the "Record on Binzhou", the people once prayed to the Xuanwu Emperor, so Xuanwu Emperor is also one of them. In addition, because Jade Emperor, Erlang God and Guandi belong to the multi-party spirits in the hearts of the people, they will also tell them that there is no rain, in order to degrade and moisten the fields, so they can also pray for rain.

\subsubsection{Places of rain praying at various places}

For example, the "octagonal well" in Binzhou, the "Ling Pei Hou" in Boxing County, the "Sheng Pool" in Lijin County, the "Luanqiu" in Guangrao County, the "Shuishui Spring" in Zouping County, and the "Five Dragons" in Changshan County Tang "Induction Temple", "Dragon Mother Well" in Huimin County, "Water Temple" in Putai County. The gods in these places specialize in the management of rainfall and lightning, so every time there is a drought, they will come to pray for rain.

\subsubsection{The custom of praying for rain shows three characteristics}

(1) The motive for praying for the rain is to relieve suffering and express people's worries about the long drought and the rain and the longing for a good life.

(2) Extensive participation in the rain praying

Regardless of the emperor or the local people's officials, regardless of the participation of men, women and children, people hope to pray for rain through them, to impress the gods. This activity was listed as a major event with a wide range of participants.

(3) Praying for the rain shows the anxiety when people face disaster hunger, and it also reveals the unity of folk beliefs and mutual recognition. There is a concept of heaven and human induction. According to this concept, natural disasters in the human world are caused by improper behavior of human beings.

\section{Two Famous Epidemic Disasters and Folk Beliefs in History}

\subsection{The harm of "black death" and folk beliefs}

In 1348, Spain, Greece, Italy, France, Syria, Egypt and Palestine all erupted the "black death", of which 56,000 people died in Marseille, France. In Avignon, there are 7,000 residential people left their house, and the fields were abandoned, all due to the disease. At that time, the doctors had been actively working on various treatments: laxatives, emetics, etc., and they even used advanced methods at the time to prevent the spread of the disease. However, death still spread everywhere. 
Some people thought that human greed had attracted the punishment of the gods. They whipped each other with iron-tip whip and sang "I am guilty". This matter has been circulating for a long time but it is now untested. In the 100 years of the 14th century, the Black Death claimed 25 million lives in Europe, resulting in a 25\% reduction in European population.

However, the cause of the disease is attributed to human reasons, human sin, and self-punishment. This has something in common with the views of heaven and man.

\subsection{The spread of the infectious plague and the origin of the Lyon Festival of Lights}

There is a legend in Lyon that has been circulating for a long time. In 1643, when the plague spread, the speed was very fast, people were always threatened with death, people were afraid and panicked. The city councillors solemnly promised to the Virgin in the church in the city that if Lyon City could escape this disaster, it would call the city to pay tribute to the Virgin at this time of the year. Later, the plague gradually receded in the city, and many people avoided the catastrophe. Since then, every year, every household will light candles outside the window on December 8th. The event will last for three to four days to thank God for his pity and express gratitude and commemoration. People came from all directions to line up the team, lit the candles, and the marching team slowly marched straight into the church to tribute to the Virgin. In addition to gratitude, tribute and celebration, Lyon's Festival of Lights has now become a festival of lighting art.

\section{The Enlightenment of Folklore Belief in Crisis Response to Education}

The loss and suffering caused by drought or plague were unprecedented. The population had fallen sharply, the fields were abandoned, the houses are deserted, and everyone was always worried about safety and worrying about survival. People were looking for reasons, reflecting on their own mistakes and asking if they were the punishment of their own guilt. No one wanted to sit still, people wanted to do something to stop it, so they hoped for the protection of the unknown mysterious power. The following two methods are common:

First, at this time, people will sin and punish themselves. The prosperous sun and the self-whipping are all reasonable.

Second, People pray to God. This is another way to weather the storm when the power of the people cannot be controll crisis from the nature. This is seen as the initial motivation for folk belief activities in times of crisis.

In the contemporary era, with the development of social technology and education, it is necessary to enhance the ability to withstand disasters. The following inspirations are given to education:

First, we should persist in emphasizing the belief in science, the development of science, and the expansion of the proportion of science subjects in basic education and early higher education, so that the population receiving science education will increase substantially, and the critical moment can play a positive role.

Second, we should adhere to the universal lifelong system of science education, people have mastered more natural meteorological knowledge and medical knowledge, and have more and more in-depth analysis and experimentation on drought, disease and other issues. The tools are becoming more refined, so the ability of human beings to cope with the crisis will become stronger and stronger with the cooperation and help of all parties.

Third, we should adhere to the combination of education and practice drills, establish the operation of crisis plan operations, connect theory with actual practice, and look at problems with developmental perspectives. For example, it is very successful to carry out fire drills for primary 
school students in elementary schools.

Fourth, See the essence through the phenomenon, carry out education and propaganda, tell people to encounter crisis, find the cause correctly, do not blame themselves, do not blame, and look at the world with an objective attitude.

All in all, there is no crisis for no reason, and things always have a context. When faced with crisis, we should not suspect but to minimize losses, which should also start from basic education. This is the most important enlightenment of the folk belief activities in the crisis moment to education.

\section{References}

[1] Wu Yuhua, Chen Haiqiong. Analysis of Hakka Folk Beliefs and Folk Sports [J]. Sports Culture Guide, 2014(06): 55-58.

[2] Wei Qin.Theory and Practice of Human Settlements Construction System in the Loess Plateau [D].Zhejiang University.2008

[3] Dai Yan. Research on the Adaptive Protection of Historical and Cultural Heritage in Baqi Ancient Town [D]. Chongqing University.2008

[4] Ying Zhen. Economic Analysis of Urban Historical and Cultural Heritage [D]. Tongji University. 2008

[5] Wang Jushan. Study on the Intangible Cultural Heritage Theory and Museum Protection of Handicrafts [D].Shandong University. 2007

[6] Wang Shusheng. Study on the Construction of Human Settlements in Historical Cities along the Yellow River and Shanxi Province [D].Xi'an University of Architecture and Technology.2006

[7] Luo Yong. Hakka Chuzhou [M]. Nanchang: Jiangxi People's Publishing, 2004: 11-9.

[8] Zhong Jingwen, editor-in-chief. Introduction to Folklore [M]. Shanghai: Literature and Art Publishing House, 2002:187.

[9] Jiao Shujun. Behind the Faith of Gods: Reality and Vision-Based on the Investigation and Analysis of Wenzhou [J]. Chinese Culture Forum, 2010(1):104-111.

[10] Zhu Tianshun. A Preliminary Study of Ancient Chinese Religions [M]. Shanghai: Shanghai People's Publishing, 1988.

[11] Xu Xiaorong.The Origin and Function of Hakka's Original Ecological Folk Sports Activities: A Field of Vision of Sports Anthropology_-Taking Wuhuolong as an Example [J]. Sports and Science, 2012, 33 (5):27-29.

[12]Shang Qiuhua. Traceability of Lion Dance Culture [J].Journal of Nanjing Institute of Physical Education, 2004, 18 (6):183-184.

[13] Chen Xiao-ping, Liu Min-fang, Wang Jia-wu. The Changing Trend of the Revival of Contemporary Folk Beliefs [J].Journal of Shaanxi Institute of Socialism, 2016(03):30-31. 